\title{
The influence of the piercing punch profile on the stress distribution on its cutting edge
}

\author{
Dominik Wojtkowiak ${ }^{1, *}$ and Krzysztof Talaśka ${ }^{1}$ \\ ${ }^{1}$ Chair of Basics of Machine Design, Poznan University of Technology, ul. Piotrowo 3, 60-965 \\ Poznań, Poland;
}

\begin{abstract}
Modifying the piercing punch profile may have a positive effect on the belt perforation process. Using the proper shape of the tool may reduce the perforation force and improve the quality of the holes. However, complex geometry of the punch can also cause an adverse stress distribution, which leads to a faster tool wear. In the presented paper, several different piercing punch profiles were tested using FEM analyses in ABAQUS and the obtained stress distributions along its cutting edges were analyzed. For the selected group of the piercing punches, the influence of variable geometrical features (a radius of rounding, an angle of chamfering or a depth of the bowl) on the stress distribution were also shown. Based on the results, it is possible to predict how modifying the punch profile will affect the shortening of the tool life, compared to the basic flat-end cylindrical piercing punch. The following research can be useful in the design process of the punching tools used for vacuum conveyor belts perforation.
\end{abstract}

Keywords: belt, perforation, punching, tool optimization, polymer composite

\section{Introduction}

Due to the variety of the construction, and as a result the mechanical properties of the polymer composite belts, which are subject to the perforation process (Fig. 1), it is very difficult to design the universal tool for each type of belt [1-3]. Basically, we can distinguish three groups of belts: the elastic light belts with polyurethane, PVC or rubber core, which can be reinforced by fabrics, the rigid belts with increased strength, whose core is made of a polyamide film protected by polyamide fabric gaskets and the durable and rather flexible polyurethane belts reinforced with aramid fiber cord [2-4] (most common as toothed belts [5], but also as v-belt or round belt [6]). Each group of belts provides different technical issues connected with the perforation process, which have an influence on the perforation parameters and the tool design. Since perforated belts (Fig. 2) appear in various widths, lengths, shapes or structures and multiple perforation patterns and hole diameters are used, the design of the automated perforating machines is much more difficult. However, designing the proper tool which will be able to minimize or eliminate all hole defects for most types of belts and will provide the

\footnotetext{
${ }^{*}$ Corresponding author: dominik.wojtkowiak@put.poznan.pl

Reviewers: Grzegorz Domek, Marian Dudziak
} 
lowest possible perforation force and still maintain long enough tool life may facilitate the design phase. Additionally, by combining it with proper process parameters, it should greatly improve the manufacturing process and yield both economic and technical benefits. This is why the presented research is important for both the industrial and scientific approach to the subject.

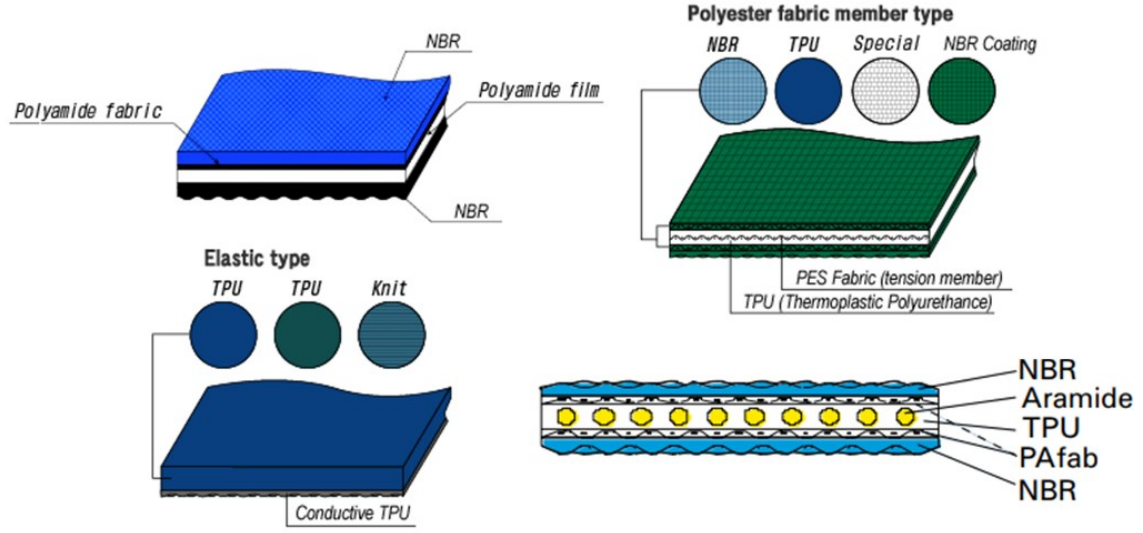

Fig. 1. Variety of the construction of the multilayer polymer composite belts $[7,8]$

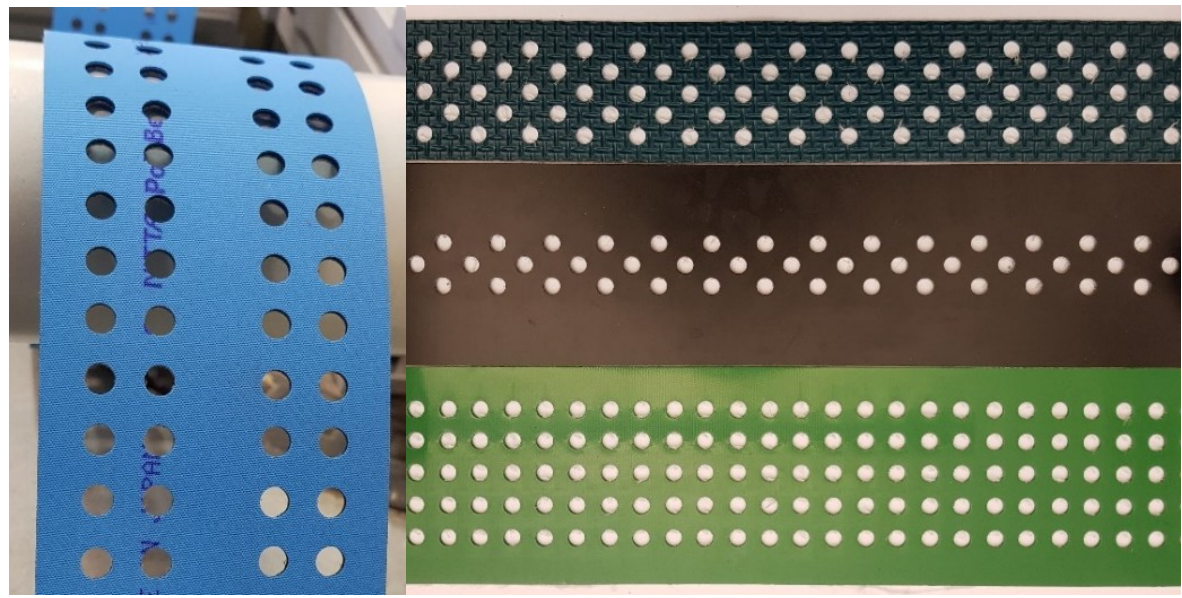

Fig. 2. Examples of the perforated belts with various perforation patterns

One can find in the scientific literature examples of the influence of the geometrical features of the tools on the process parameters, especially the maximum force necessary to perform the process. Technically, the punching process with a closed contour tool is a combination of the compression of the scrap and shearing of the material. Because of that it is possible to find some similar correlations between the geometrical parameters of the tools and the necessary force or torque in cutting [9] and agglomeration [10-14]. Since polymer composite belts may have various structures, the main resemblance can be found in natural polymers [9-11, 15] and unclassical materials [12-14].

Based on the previous research [2], it was proved that proper modification of the piercing punch profile may greatly reduce the perforation force and the concave group of modified punches provide the best combination of force reduction and quality of the hole, especially the spherical bowl piercing punch. Since the convergent shape of the die channels in the agglomeration process may reduce the force [14], the authors decided to compare the above mentioned shape of the piercing punch with the one with conical bowl. 
In the presented research, the authors have compared both punches based on the force, quality and tool wear criteria. Due to the technical difficulties to evaluate the tool life in belt perforation, since the number of cycles may exceeds $1,000,000$ cycles, the authors decided to use the FEM analyses and the fact that the fatigue strength of the tool depends on the stress distribution [16]. In section 2, the authors have presented the methodology of research for both empirical tests used to determine the peak perforation force value as well as to evaluate the quality of the holes and above-mentioned FEM analyses. The results of all the punching tests are presented respectively in section 3 and 4 along with the short discussion. The paper ends with a short summary in which the main conclusions are stated.

\section{Methodology of research}

In order to perform all the necessary punching tests, the authors have used a designed test stand [2] in the form of a punching die (Fig. 3) and a properly manufactured set of tools - the die with cylindrical channel (Fig. 3 - 9) and two piercing punches: with conical (Fig. 3 - 10a) and spherical (Fig. $3-10 \mathrm{~b}$ ) bowls. To make it possible to compare the results, both punches have the same depth of the bowl, which equals $H=2 \mathrm{~mm}$ and outer diameter $D=10 \mathrm{~mm}$. The punching die is mounted on the strength testing machine MTS Insight 50, with the load capacity of $50 \mathrm{kN}$. During the tests the force-displacement characteristics were recorded and the test was repeated 5 times for each tool and type of belt. In the empirical research, 8 different types of belt were used, among which there were one representative of elastic light belts (LAB12E), one of toothed belts (T10K), and six from rigid belts with increased strength group (M500, SG500, XH500-6, TFL7S, TFL10S, TFL15S). All these belts vary in their thickness and mechanical properties in order to cover a wide spectrum of variables in the obtained results. Each belt was prepared as a rectangular specimen with dimensions $30 \times 150$, in which five holes $20 \mathrm{~mm}$ spacing were made. The velocity of the punch was established at $0.5 \mathrm{~mm} / \mathrm{s}$ in order to maintain the quasi-static behaviour of the perforation process.
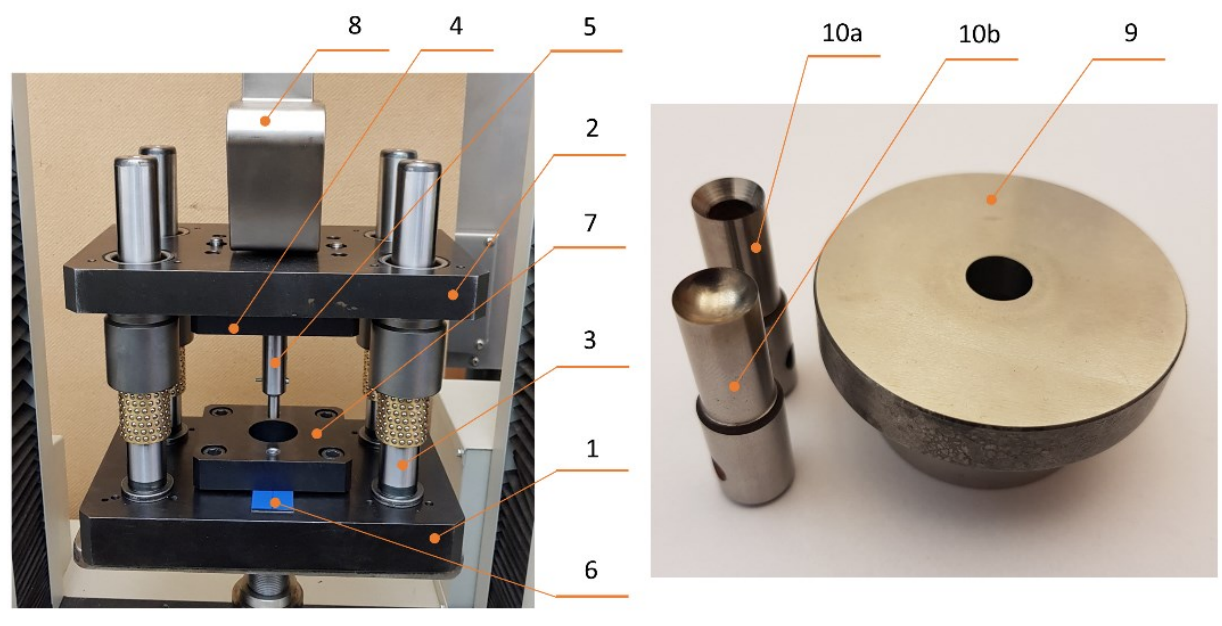

Fig. 3. Construction of the punching die along with the tools used during the empirical tests: 1 - base, 2 - head block, 3 - linear ball guide (column, sleeve and ball bushing), 4 - punch plate, 5 - punch chunk, 6 - belt specimen, 7 - blank holder, 8 - strength testing machine grip, 9 - die, 10a - conical bowl piercing punch, $10 \mathrm{~b}$ - spherical bowl piercing punch

Modelling and computer simulations are one of the most effective method of studying and optimizing the process or the machine construction [17]. For the FEM analyses presented in the paper the ABAQUS software was used, which is widely used in modelling different 
mechanical dynamic problems [18-20]. In Fig. 4 both FEM models for spherical and conical bowl punches created in ABAQUS Explicit are presented. Because the punch and the die are axisymmetric components, the $3 \mathrm{D}$ analysis was simplified to $2 \mathrm{D}$ axisymmetric analysis, which makes it possible to dense the mesh grid without extending the computational time. The FEM model consists of four parts, where three of them are deformable (punch, die and belt), while one is a rigid body (blank holder). The material of the belt was determined as an elastic-plastic one, with density $1140 \mathrm{~kg} / \mathrm{m}^{3}$, Young Modulus $E=310 \mathrm{MPa}$ and Poisson ratio $v=0.2$. The plastic properties were specified with tabular data obtained from the empirical test. All other parts were made of steel (density $7850 \mathrm{~kg} / \mathrm{m}^{3}$, Young modulus $E=2.1 \mathrm{e}^{6} \mathrm{MPa}$ and Poisson ratio $v=0.33$ ). Three interactions were specified between: the inner surface of the bowl and top surface of the belt, the bottom surface of the belt and top surface of the die as well as the top surface of the belt and bottom surface of the blank holder as a penalty contact method with finite sliding. In order to model the movement of the punch, its top edge was subject to a boundary condition $\mathrm{BC} 1$ and the velocity in vertical axis was specified as $0.5 \mathrm{~mm} / \mathrm{s}$. Boundary condition BC2 was set as XSYMM while boundary conditions BC 3 and $\mathrm{BC} 4$ were set as ENCASTRE. The analysis time equals $5 \mathrm{~s}$ and the mass scaling was set with the target time increment $1 \mathrm{e}^{-6}$, which reduced the computational time, but was not significant for the obtained results.

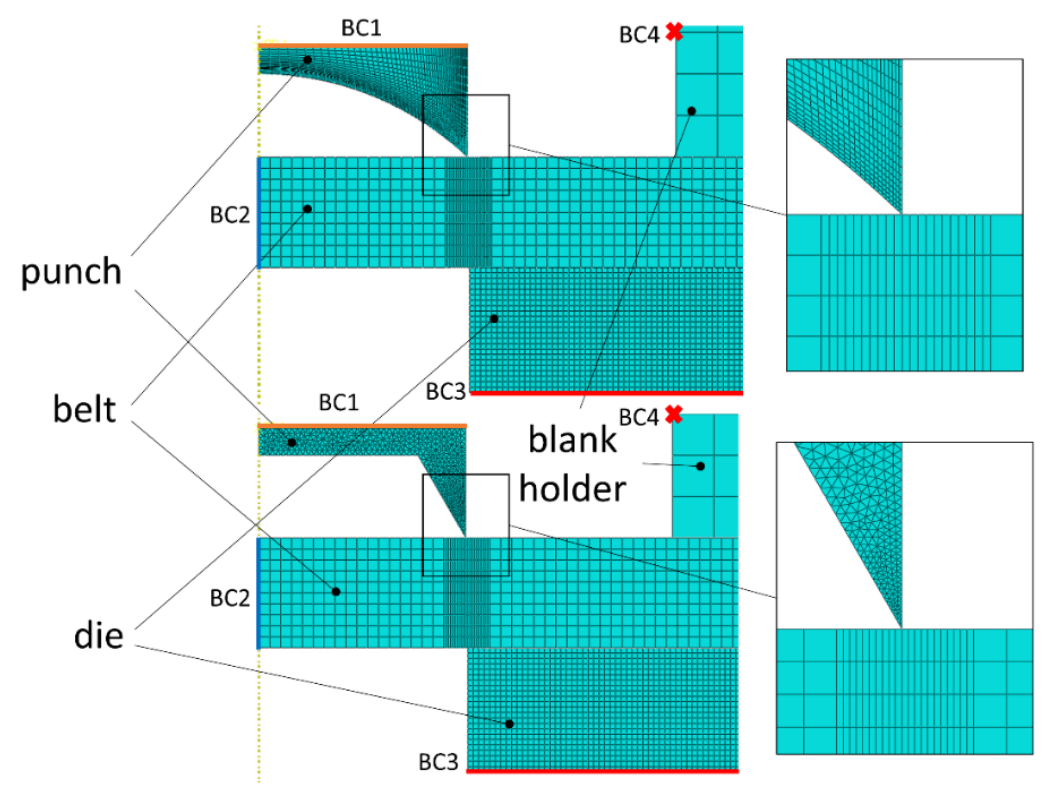

Fig. 4. FEM models in ABAQUS used for in the research

\section{Comparison of perforation force for spherical and conical bowl punches - empirical tests}

In Fig. 5 specimens of TFL10S belts perforated with both tools along the close up view on the side surface of the holes are presented. As can be observed in both cases no defects common for the punching process (conicity or ovality of the holes, fiber pull-out, uneven edge or side surface, deformation of the covers of the belt, etc. [1]) have occurred. By analysing the quality of the side surface for both piercing punches we have received a very smooth surface with almost no defects. If we analyse the hole diameter deviations $\Delta$, the differences are still hardly noticeable since in both cases it varies in a range of 0.1-0.2 mm. 
Based on the above analyses and considering the quality of the holes criteria, both tools give advantageous results, which fulfils all the requirements of the perforated belt manufacturers.

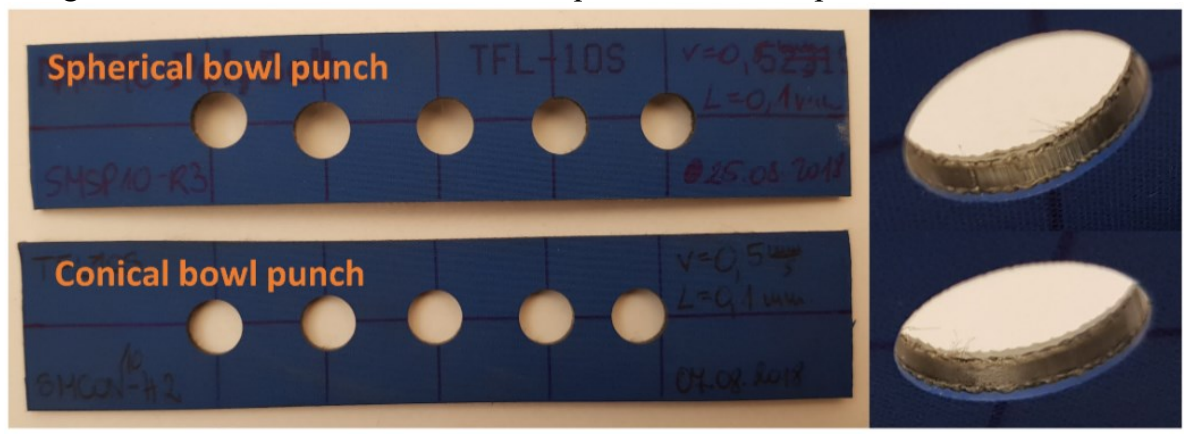

Fig. 5. Belt specimens after perforation for both spherical and cylindrical bowl punches

The comparison of the average peak values of the perforation force for both punches and 8 different types of belts is presented in Tab. 1. It can be observed that for belts with lower strength and thickness (LAB12E, M500, SG500 and T10K) the differences are negligible and may be caused by a shape deviation of a punch (ovality or multi-angularity [21]), however for more rigid belts (TFL7S, TFL10S and TFL15S) the divergence of the peak force value rises and reaches up to $23 \%$ for the strongest belt. Additionally, a huge difference may be noticed for very thick belts $(6 \mathrm{~mm})$ with lower strength, in which the difference exceeds $50 \%$. Based on the results, we can conclude that in case of the spherical bowl punch there is a strong positive correlation between the thickness of the belt and the perforation force, while for a conical one the force increases with the strength of the belt connected with the thickness of the core of the belt (polyamide film). However, it is still worth mentioning that the obtained values for both punches are rather low and compared to the flat punch, the force is reduced by up to $60 \%[2]$.

Table 1. Comparison of the perforation force peak values for spherical and conical bowl punches

\begin{tabular}{|c|c|c|c|c|c|c|c|c|}
\hline & \multicolumn{7}{|c|}{ Perforation force [N] } \\
\hline Belt type & LAB12E & M500 & SG500 & T10K & TFL7S & TFL10S & TFL15S & XH500-6 \\
\hline $\begin{array}{c}\text { Thickness } \\
{[\mathbf{m m ]}}\end{array}$ & 2.1 & 2.5 & 1.1 & $\begin{array}{c}2.05- \\
4.5\end{array}$ & 2.4 & 2.65 & 3.1 & 6 \\
\hline $\begin{array}{c}\text { Core } \\
\text { thickness } \\
\text { [mm] }\end{array}$ & - & 0.5 & 0.5 & - & 0.7 & 1 & 1.5 & 0.5 \\
\hline $\begin{array}{c}\text { Spherical } \\
\text { bowl } \\
\text { punch }\end{array}$ & 927 & 1240 & 939 & 977 & 1498 & 1862 & 2502 & 3024 \\
\hline $\begin{array}{c}\text { Conical } \\
\text { bowl } \\
\text { punch }\end{array}$ & 917 & 1222 & 1106 & 1118 & 1398 & 1570 & 1930 & 1395 \\
\hline
\end{tabular}




\section{Stress distribution on the cutting edge - FEM analyses}

The stress distribution analyses were made in four different stages of perforation for a TFL10S belt:

- first stage, in which the piercing punch starts to penetrate the NBR coating of the belt $(x=0.125 \mathrm{~mm})$,

- second stage, in which the piercing punch penetrates the polyamide fabric protective gaskets $(x=0.5 \mathrm{~mm})$,

- third stage, in which the piercing punch reaches the polyamide film core of the belt $(x=1.25 \mathrm{~mm})$,

- fourth stage, which occurs right before the fracture of the belt $(x=2.25 \mathrm{~mm})$.

In Fig. 6 the stress distributions on a cutting edge along with the peak Mises stress values obtained in FEM analyses for a spherical bowl punch are presented, while in Fig. 7 the corresponding data for a conical bowl punch is shown. In Fig. 8 and Fig. 9 the stress distributions on the inner surface of the punch bowls in the final stage of analyses for spherical and conical bowl punches respectively are presented.

Based on the results, we can observe that at the beginning of the perforation in both cases the stress concentration is visible on the tip of the cutting edge profile and the outer surface of the piercing punch. As the penetration propagates, the stress concentration moves to the inner surface of the punch bowl, while the outer surface is unloaded. The main difference between the punch profile is that for the conical bowl punch the tip of the cutting edge is subjected with the highest stress regardless of the penetration value, while for a spherical bowl punch the stress is distributed on the bigger surface as the penetration propagates. Additionally, we can observe that on the inner surface of the conical bowl the stress distribution is more uniform than for a spherical bowl, especially for large penetration values. It may be the reason, while for thicker belts the perforation force is lower if we use a conical bowl punch.
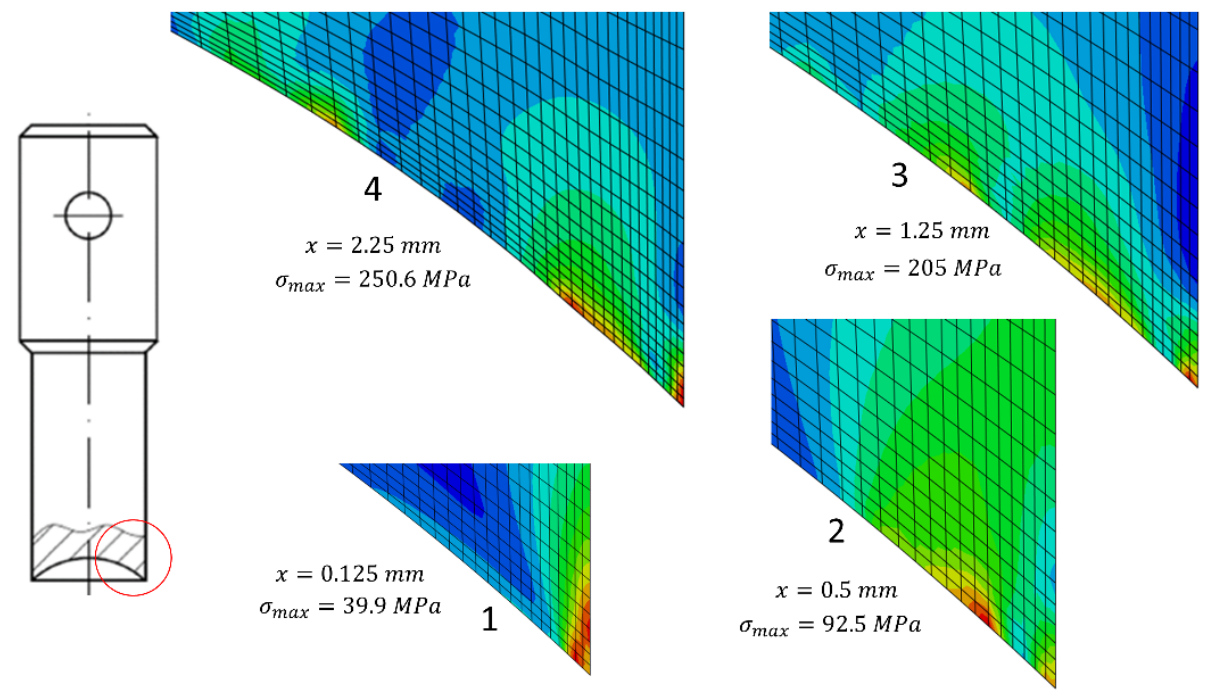

Fig. 6. Four stages of stress distribution in a spherical bowl punch during belt punching - FEM analysis results 

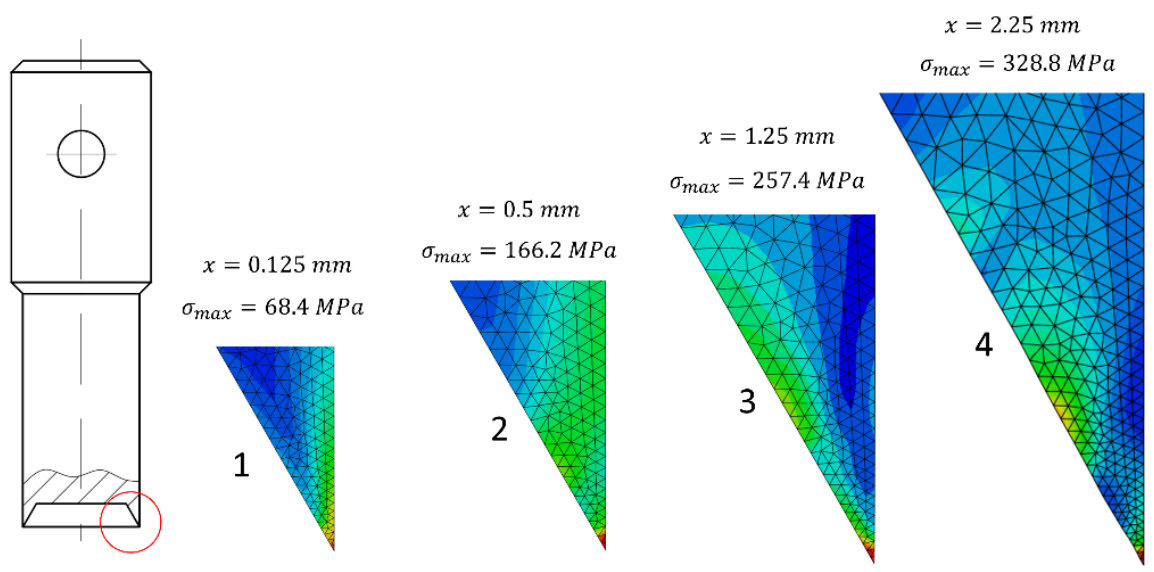

Fig. 7. Four stages of stress distribution in a conical bowl punch during belt punching - FEM analysis results
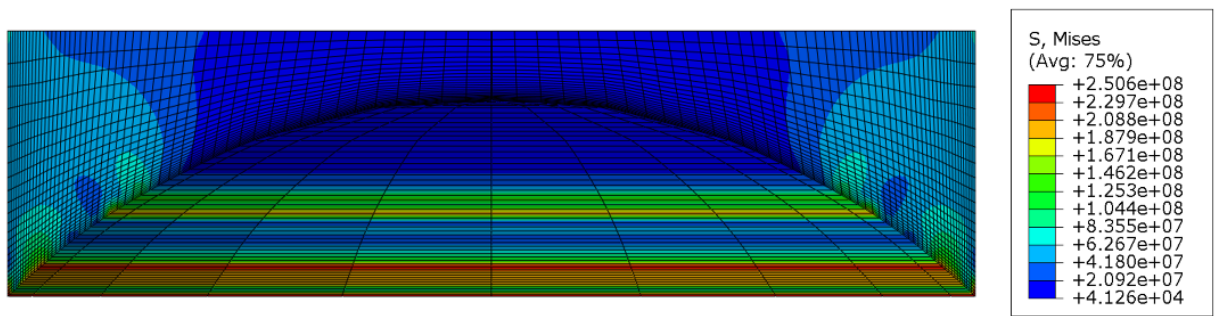

Fig. 8. Stress distribution in a spherical bowl punch during belt punching right before the fracture occurs - FEM analysis results
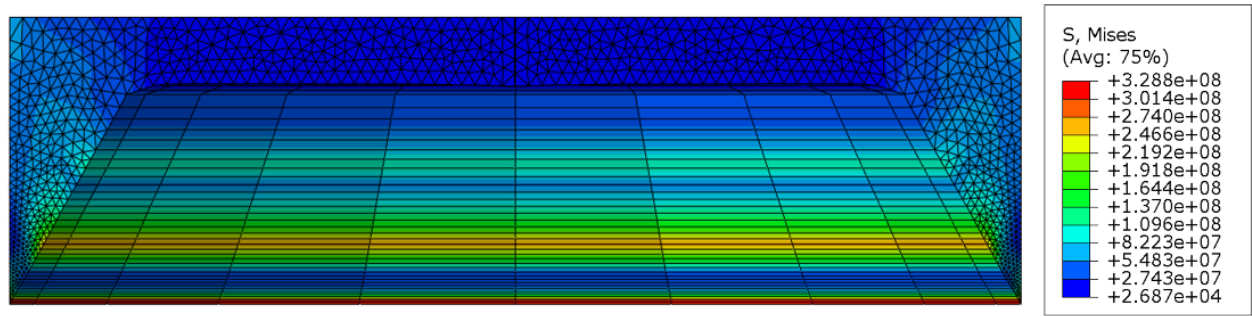

Fig. 9. Stress distribution in a conical bowl punch during belt punching right before the fracture occurs - FEM analysis results

Considering the tool life, the most important factor is the quality of the cutting edge and its sharpness, which may be decreased as a result of the rounding caused by frictional work and fatigue wear. Because of that, the most important is the peak value of the stress on the tip of the punch profile. The characteristics in Fig. 10 present the correlations between the depth of the penetration and the Mises stress on the cutting edge for both of the analysed punches. Based on the results, we can conclude that the tool life of the spherical bowl punches should be longer than the conical one since the peak stress value is about $25 \%$ lower. Additionally, at the beginning of the perforation we can see very sharp growth of the stress value, which may be especially dangerous if we consider the dynamics in the real industrial process, in which the punch velocity exceeds $40 \mathrm{~mm} / \mathrm{s}$. 


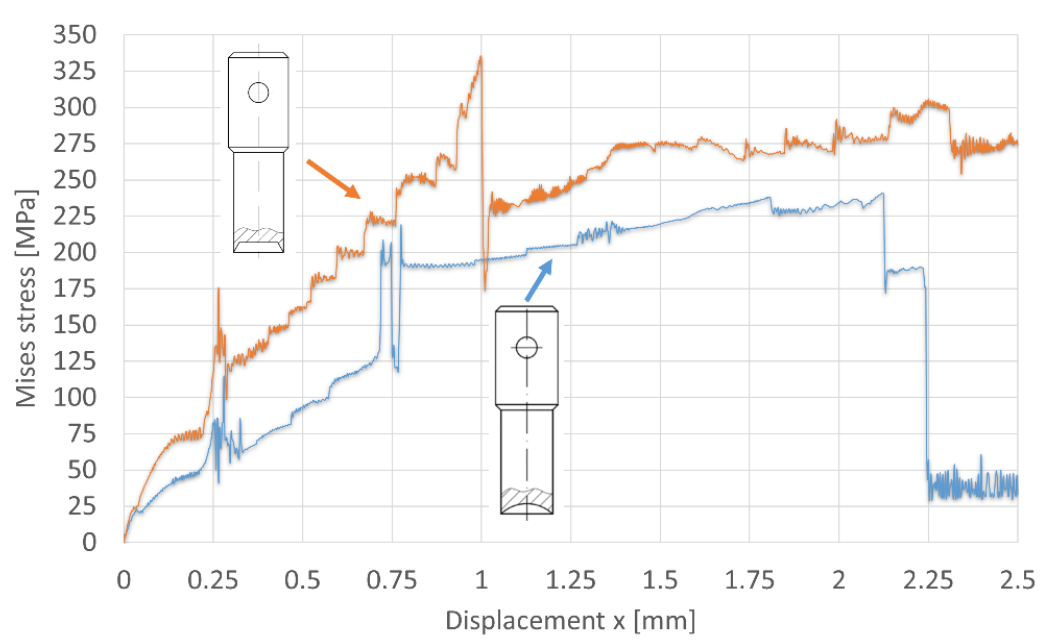

Fig. 10. Comparison of Mises stress on the cutting edge in function of displacement for spherical and conical bowl punches - FEM analysis results

\section{Conclusions}

The presented research proved that concave profiles of piercing punches should be considered as a possible effective tool for composite belt punching. The perforation force can be reduced up to $60-70 \%$ with the use of a proper punch profile. Both spherical and conical bowl punches provide proper quality of the hole and can be certainly used in the belt perforation. The stress distribution analyses showed that the spherical bowl punches may be characterized by a longer tool life since they have a more advantageous stress distribution, which means that despite slightly higher peak perforation force they are still considered as an effective punch profile for polymer composite belts. However, for certain cases like very thick belts it is recommended to use the conical bowl punches in order to minimize the perforation force. These belts very often have thick NBR coating, which will damp the negative effect of the dynamic impact of the punch on the belt, and because of that it should not affect the tool wear, but will greatly reduce the perforation force. The presented results showed that an investigation of the influence of the geometrical features of the tools may greatly improve the technological process and will provide a lot of useful data, which can be used in the design process of the machines used for belt perforation.

\section{References}

1. D. Wojtkowiak, K. Talaśka, I. Malujda, G. Domek, Analysis of the influence of the cutting edge geometry on parameters of the perforation process for conveyor and transmission belts. MATEC Web of Conferences 157, 01022 (2018)

2. D. Wojtkowiak, K. Talaśka, I. Malujda, G. Domek, Estimation of the perforation force for polymer composite conveyor belts taking into consideration the shape of the piercing punch. The International Journal of Advanced Manufacturing Technology 98, 9-12, 2539-2561 (2018) https://doi.org/10.1007/s00170-018-2381-3

3. D. Wojtkowiak, K. Talaśka, I. Malujda, G. Domek, Vacuum conveyor belts perforation - methods, materials and problems, Mechanik 12/2017, 1138-1142 (2017) https://doi.org/10.17814/mechanik.2017.12.192 
4. K. Talaśka, D. Wojtkowiak, Modelling a mechanical properties of the multilayer composite materials with the polyamide core. MATEC Web of Conferences 157, 02052 (2018)

5. G. Domek, A. Kołodziej, Design of the tendon structure in timing belts, Procedia Engineering 136, 365-369 (2016)

6. K. Wałęsa, I. Malujda, K. Talaśka, Butt welding of round drive belts. Acta Mechanica et Automatica 12 (2), 115-126 (2018)

7. Nitta Industries website - www.nitta.co.jp, (Access date: 06.08.2018)

8. Wilhelm Herm. Müller, Nitta Industries - polish catalog, In: www.whm.pl (Access date: 06.08.2018)

9. D. Wilczyński, K. Talaśka, I. Malujda, P. Jankowiak, Experimental research on biomass cutting process. MATEC Web of Conferences 157, 07016 (2018)

10. K. Talaśka, I. Malujda, D. Wilczyński, Agglomeration of natural fibrous materials in perpetual screw technique - a challenge for designer. Procedia Engineering, Vol. 136, 63-69 (2016)

11. D. Wilczyński, I. Malujda, K. Talaśka, R. Długi, The study of mechanical properties of natural polymers in the compacting process. Procedia Engineering, Vol. 177, 411-418 (2017)

12. J. Górecki, I. Malujda, K. Talaśka, M. Kukla, P. Tarkowski, Influence of the Value of Limit Densification Stress on the Quality of the Pellets During the Agglomeration Process of $\mathrm{CO}_{2}$. Procedia Engineering 136, 269-274 (2016)

13. J. Górecki, I. Malujda, K. Talaśka, Investigation of Internal Friction of Agglomerated Dry Ice. Procedia Engineering 136, 275-279 (2016)

14. J. Górecki, I. Malujda, K. Talaśka, D. Wojtkowiak, Dry ice compaction in piston extrusion process. Acta Mechanica et Automatica 11, 4, 313-316 (2017)

15. I. Malujda, D. Wilczyński, Mechanical Properties Investigation of Natural Polymers. Procedia Engineering Vol. 136, 263-268 (2016)

16. A. Kocanda, P. Czyżewski, Numerical analysis of abrasive wear of forging dies. In: K. Mori, Simulation of Material Processing: Theory, Methods and Applications, 421-424 (2001)

17. R. Dyja, E. Gawronska, A. Grosser, P. Jeruszka, N. Sczygiol, Estimate the Impact of Different Heat Capacity Approximation Methods on the Numerical Results During Computer Simulation of Solidification. Engineering Letters 24, 2, 1-14 (2015)

18. M. Dudziak, G. Domek, A. Kołodziej, K. Talaśka, Contact Problems Between the Hub and the Shaft with a Three-angular Shape of Cross-section for Different Angular Positions. Procedia Engineering 96, 50-58 (2014)

19. M. Žmindák, Z. Pelagića, P. Pastoreka, M. Močilana, M. Vybošt’oka, Finite element modelling of high velocity impact on plate structures. Procedia Engineering 136, 162-168 (2016)

20. T. Domański, A. Sapietová, M. Sága, Application of Abaqus software for the modeling of surface progressive hardening. Procedia Engineering 177, 64-69 (2017)

21. M. Dudziak, A. Kołodziej, G. Domek, K. Talaśka, Multi-angularity - identification of parameters and compatibility conditions of the axisymmetric connection with form deviations. Procedia Engineering 177, 431-438 (2017) 